\section{B A Institute of \\ YK Business Administration \\ 六下 \\ Karachi \\ Leadership and Ideas for Tomorrow}

Business Review

Volume 9 Issue 1 January-June 2014

$1-1-2014$

\title{
Perceived importance of job analysis influencing motivation and competencies among blue-collar and white-collar employees
}

A.K.M. Mominul Haque Talukder North South University, Bangladesh

Follow this and additional works at: https://ir.iba.edu.pk/businessreview

Part of the Experimental Analysis of Behavior Commons

(c) (i)

This work is licensed under a Creative Commons Attribution 4.0 International License.

\section{Recommended Citation}

Talukder, A. (2014). Perceived importance of job analysis influencing motivation and competencies among blue-collar and white-collar employees. Business Review, 9(1), 79-91. Retrieved from https://doi.org/10.54784/1990-6587.1229 
ARTICLE

\title{
PERCEIVED IMPORTANCE OF JOB ANALYSIS INFLUENCING MOTIVATION AND COMPETENCIES AMONG BLUE-COLLAR AND WHITE-COLLAR EMPLOYEES
}

\author{
A.K.M. Mominul Haque Talukder \\ North South University, Bangladesh
}

\begin{abstract}
Job analysis is pivotal in identifying the tasks that new recruits are expected to undertake. It is useful to examine whether or not existing job descriptions, person specifications or competency profiles are appropriate for future needs. The study explored perceptual differences of job analyses significance within blue-collar employees (BCEs) and white-collar employees (WCEs) in a manufacturing firm. Data were obtained based on structured questionnaire. Results indicated significant positive relationship of performance appraisal with competencies in case of white-collar employees. In contrast, training was positively related to competencies with regard to blue-collar employees. Other dimensions including selection process, rewards and job description have no relationship with motivation and competencies. The findings commend that investigating these dimensions in similar or different manufacturing settings might provide firms with the potent to improve motivation and competencies significantly.
\end{abstract}

Keywords: Job Analysis, Performance Appraisal, Training, Motivation, Competencies.

\section{Background}

Job analysis refers (Armstrong, 2002) to the process of collecting, analyzing, and setting out information about the contents of job in order to provide the basis for a job description and data for recruitment, training, job evaluation and performance management. Job analysis is the most useful tools for gathering information and developing content valid and legally defensible selection procedures for a wide variety of jobs (Harvey, 1991). A fundamental assumption of traditional job analysis is that the information about a job as it presently exists is useful for developing selection procedures because the job will be similar in the future (Schneider and Konz, 1989). Unfortunately, current trends in organizations (e.g. downsizing and reorganization) often result in the creation of new or re-designed jobs (Howard, 1996). In these situations, the assumption of job stability may often be untenable and traditional job analysis techniques may neither be possible nor be appropriate. As a result, there is a need for job analyst to develop new methods for identifying the key tasks and the knowledge, skills and abilities (KSAOs) that are required for jobs that are changing (Landy et al., 1995). Broadly defined, job analysis involves collecting data about observable job behaviors, and delineating the knowledge, skills, abilities, and other characteristics needed to perform the job (Cascio and Aguinis, 2005).

Strategic job analysis is a systematic process of identifying and describing the important aspects of a job and the characteristics a worker needs to do his or her job well (Phillips and Gully, 2009). It ensures that randomness is reduced and learning or behavioral 
change takes place in structured format. Employee selection is the process of putting right person on right job. It is a procedure of matching organizational requirements with the skills and qualifications of people. Effective selection can be done only when there is effective matching. Competencies are the measurable or observable knowledge, skills, abilities, and behaviors critical to successful job performance (Mullen, 2005). Choosing the right competencies allow employers to plan how they will organize and develop their workforce, determine which job best fits their business needs, recruit and select the best employees, manage and train employees effectively and develop staff to fill future job performance.

The research focuses on factors affecting perception of job analysis in a manufacturing company of Bangladesh. Aspects like performance appraisal, reward, training, job description, selection process, motivation and competency are linked with the success of a company and interdependent on each other for initiating and sustaining a company's success. The objective of the study is to carry out a quantitative study of how the company is affected by the perceptual variation of two cohorts e.g., blue-collar employees and white-collar employees and subsequently moderating job analysis. The antecedents of job analysis would influence motivation while leveraging human capital. As well as the study would contribute to the existing literature and put forward new direction to manage human resources.

\section{Literature Review and Hypotheses}

Performance appraisal usually involves 'evaluating performance based on the judgments and opinions of subordinates, peers, supervisors, other managers and even workers themselves' (Jackson and Schuler, 2003). Dubinsky, Skinner, and Whittler (1989) contend that appraisals can be used to determine rewards, provide managerial feedback, help to monitor the effectiveness of human resource management decisions, help to evaluate training and development needs, and provide human resource planning and budgeting information. An organization's performance appraisal system is an important, but often neglected, tool for managing the effectiveness and efficiency of employees (Ilgen and Feldman, 1983; Erdogan, 2002).

Bitter and Gardner (1995) reported the tendency of supervisors to attribute the cause of poor performance to low motivation. Motivation represents an employee's desire and commitment to perform and is manifested in job related effort. It is the factor that keeps the human active and makes them feel good about their job. Competency is the combination of knowledge, skills and behavior used to improve performance; or is the state or quality of being adequately or well qualified, having the ability to perform a specific role. Motivation is a driving force behind a successful employee. If there is no motivation employee might lose enthusiasm. If manager's assessment is incorrect and poor performance is related to ability rather than motivation, the response to increased pressure will worsen the problem. If poor performers feel that management is insensitive to their problems-that they lack resources, adequate training, or realistic time schedules-they may respond counterproductively to any tactics aimed at increasing their efforts. Motivation is important not only to increase productivity but also to elevate competencies of employees in the organizations.

The use of competencies to identify high-performing people, or outstanding employees, has gradually become widespread in human resource management (Lawler, 1994; Ulrich, 1997). Those characteristics that set these employees apart provide the basis for recruitment, selection, and development strategies that are effective and provide a high return on investment. In rapidly changing business environments, organizations are recognizing the 
value of a workforce that is not only highly skilled and technically adept, but more importantly, a workforce that can learn quickly, adapt to change, communicate effectively, and foster interpersonal relationships. These characteristics, or competencies, are critical to organizational survival, productivity, and continual improvement. Using competencies as the basis for staffing provides the flexibility needed to select and place individuals where they can best serve the organization. One of the strengths of competency models is that they are often linked to the business goals and strategies of the organization (Rodriguez et al., 2002). As scholars (Howard, 1996; Cascio, 1996) have indicated, the changing nature of work requires evaluating worker competencies that are different from those evaluated in the past. Predictions are that work will become more difficult, more fluid, and more interconnected. As a result, the competencies needed by future workers will change. Employees will require to be smart, to be able to learn and grow, but at the same time be adaptable, responsible, and able to work with others.

\section{Performance Appraisal}

The efforts of employees can determine the success and survival of an organization (Drucker, 1994; Barney, 1995), and appraisal is potentially one way in which those efforts can be aligned with the aims of an organization, employees can be motivated and their performance managed (Cook and Crossman, 2004). As Moravec (1996) puts it: 'effective performance management can serve as the key lever of change that boosts individual and team accomplishment'. Performance appraisal is a process that identifies, evaluates and develops employee performance to meet employee and organizational goal. It focuses on employee's performance improvement. It is the process of obtaining, analyzing, and recording information about the relative worth of an employee to the organization. Periodic reviews help supervisors gain a better understanding of each employee's abilities. The goal of the review process is to recognize achievement, to evaluate job progress, and then to design training for the further development of skills and strengths. Performance appraisal typically involves measuring how well an individual employee is doing their job against a set of criteria. It also helps to judge who need promotion, training and so forth.

Dowling et al. (1999) state that international performance management is a strategic HRM process that enables the MNCs to evaluate and continuously improve individual, subsidiary unit and corporate performance against clearly defined, pre-set objectives that are directly linked to international strategy. Performance appraisal is considered as one of several key elements of performance management. Cardy and Dobbins (1994) define performance appraisal as the process of identifying, observing, measuring and developing human resources in organizations. An effective performance appraisal system encourages individual performance by reinforcing organizational objectives. This is accomplished by establishing personal performance objectives that are congruent with overall organizational goals. In turn then, encouraging individual performance through performance appraisal promotes overall organizational performance (Katsanis, Laurin, and Pitta, 1996). Performance appraisal is an important process for influencing both the extrinsic and intrinsic motivations of employees and their attitudes towards companies. Thus it can be proposed that,

Hypothesis 1: Perception of effective performance appraisal practice is positively related to motivation and competencies within WCEs and BCEs. 


\section{Rewards}

Rewards, compensation and benefits are critical organizational tools whose sphere of influence reaches beyond the periphery of the individual processes. This reward is a key factor which helps employers motivates employee performances (Stone, 2002). Rewards program is designed to encourage employees to make a performance difference either individually or through teams. Taking time to recognize achievements helps staff to understand how their performance contributes to the overall objectives of the organization. Reward systems can a number of HR processes and practices, which in turn impact on organizational performance (Lewis, 2006). Rewards impact recruitment and retention (Guthrie, 2007). High wages attract more applicants, which allow greater choice over selection and hiring decisions, which in turn may reduce labor turnover (Lawler, 2000). The way in which employees are rewarded has a major influence on corporate culture. For example, reward systems that provide benefits for long-serving staff are likely to shape the existing culture into one in which loyalty is seen as central to the corporate ideology. Employees see reward systems as signaling the importance the employer places on various activities or behaviors. Therefore, reward systems have a motivational impact and must be integrated with the corporate behavior being sought. So, it can be proposed that,

Hypothesis 2: Rewards are positively related to motivation and competencies within WCEs and BCEs.

\section{Training}

Training has long been a fundamental concern in organizational contexts. As the nature of work changes, employees are increasingly required to develop a wide, mutable set of skills that are essential to the success of their organizations. Yet few workers possess the cultural competence, interpersonal skills and technological proficiency required for these changing work demands (Salas and Stagl, 2009). Training is focused on producing permanent cognitive and behavioral changes, and on developing critical competencies for job performance. Organizations make increasingly large investments in training because it serves as a powerful tool for producing the targeted cognitive, behavioral and affective learning outcomes essential for their survival (Salas and Stagl, 2009). Effective training can yield higher productivity, improved work quality, increased motivation and commitment, higher morale and teamwork, and fewer errors, culminating in a strong competitive advantage (Salas et al., 2006).

Training and employee development are vital contributors to organizational success and will continue to be so in the foreseeable future. Changes in economic forces and globalization point to the importance of human resources and skilled "knowledge workers" as key sources of sustainable competitive advantage (Drucker, 1999). Every indication is that the need for training will continue given increasing demands on organizations to boost productivity, keep pace with technological advances, meet competitive pressures, use teambased decision making and problem solving, reengineer processes, and satisfy employee development and retention requirements. With this emphasis on learning and skill development, employers hope expenditures will yield a favorable return on their investment. Studies suggest that many training and development activities are implemented on blind faith in the hope that they will produce results (Arthur et al., 2003; Robinson and Robinson, 1989). One study found that employers who were in the top quartile of their peers relative to the average training expenditure per employee experienced 24 percent higher-gross profit 
margins, 218 percent higher income generation per employee, and a 26 percent higher priceto-book value of company stock price relative to those employers in the bottom quartile (Wells, 2001). Thus, it can be proposed that,

Hypothesis 3: Training is positively related to motivation and competencies within WCEs and BCEs.

\section{Job Description}

Job descriptions provide recruits with essential information about the organization and their potential role, and without them people would apply for jobs without any form or realistic job preview (Marchington and Wilkinson, 2008). Having to outline critical job results areas or accountability profiles can help managers decide whether or not it is necessary to fill a post, and if so in what form and what level. On the other hand, vague and flexible accounts of what is needed in a job may only store up trouble if there are subsequent concerns about performance and whether or not people are doing what is expected of them. Job descriptions are lists of the general tasks, or functions, and responsibilities of a position (McNamara, 2000). Typically, they include to whom the position reports, specifications such as the qualifications needed by the person in the job, salary range for the position, etc. Job descriptions are usually developed by conducting a job analysis, which includes examining the tasks and sequences of tasks necessary to perform the job. The analysis looks at the areas of knowledge and skills needed by the job.

Typically, job descriptions are used especially for advertising to fill an open position, determining compensation and as a basis for performance reviews. Not everyone believes that job descriptions are highly useful. A job description is usually developed by conducting a job analysis, which includes examining the tasks and sequences of tasks necessary to perform the job. The analysis considers the areas of knowledge and skills needed for the job. Job descriptions help employees understand the tasks for which they are accountable so they can prioritize their work based on which duties are more critical than others. Moreover, a manager can compare an employee's performance with the job description's standards and suggest specific tasks the employee can perform better. Employers decide how much to pay employees by determining the monetary worth of their professional abilities and responsibilities. Job descriptions allow employees to reflect on their own work and ensure they are meeting a company's standards prior to undergoing a performance review with a manager. Job descriptions give managers the standards they should look for when hiring new employees. Employers typically include full job descriptions in job postings to attract qualified candidates. Companies use job descriptions to help plan which positions they can trim through a layoff or how to change the structure of a business, which affects employees' job duties. Therefore, it can be proposed that,

Hypothesis 4: An appropriate job description is positively related to motivation and competencies within WCEs and BCEs.

\section{Recruitment and Selection}

Hiring competent people is of paramount importance and this is dependent on effective recruitment and selection procedures, which aim to select the 'right' individuals and reject the 'wrong' ones. The importance of this should not be underestimated because a poor requirement decision can cost an employer an amount equal to 30 per cent of the employee's first-year earnings (Hacker, 1997). These costs can include: lower productivity; potential loss 
of clients; training costs; advertising costs; recruitment fees and redundancy packages (Smith and Graves, 2002). Recruitment and selection involves making predictions about future behavior so that decisions can be made about who will be most suitable for a particular job. Predictions must always be couched in terms of probabilities because the future is unpredictable (Bach, 2005). In addition, employee selection is the process of putting right person on right job. It is a procedure of matching organizational requirements with the skills and qualifications of people.

Effective selection can be done only when there is effective matching. By selecting best candidate for the required job, the organization will get quality performance of employees. Moreover, organization will experience less of absenteeism and employee turnover problems. By selecting right candidate for the required job, organization will also save time and money. Proper screening of candidates takes place during selection procedure. Selection process helps an organization to effectively select the right people for the organization. It is very important for the recruitment process to be unbiased, free of discrimination and to maintain equity. A good selection process reduces the cost of rerecruitment. So, it is a vital part of an organization. Successful organizations of the future will attract, engage, develop, and retain the best and brightest employees. Success will belong to those organizations who define return on investment not only in terms of profit and loss but also as the development and aggregation of human and intellectual capital (Rich, 2000). Therefore, it can be proposed that,

Hypothesis 5: Right and timely recruitment and selection process is positively related to motivation and competencies within WCEs and BCEs.

\section{Conceptual Model}

Most research studies have an explicit or implicit theory, which describes, explains, predicts or controls the phenomenon under study. Theories are linked to conceptual models and frameworks; whereas a conceptual model is more abstract than a theory and a theory may be derived from a model, the framework is derived deductively from the theory (Burns and Groves, 2001). A model is developed (Figure 1) which is derived from the review of the literature by integrating theory and research relating to different components of strategic job analysis and competency. It includes performance appraisal, rewards, training, job description, and selection process as independent variables and their relationship with motivation and competencies of the employee as dependent variables.

Figure 1: Research framework

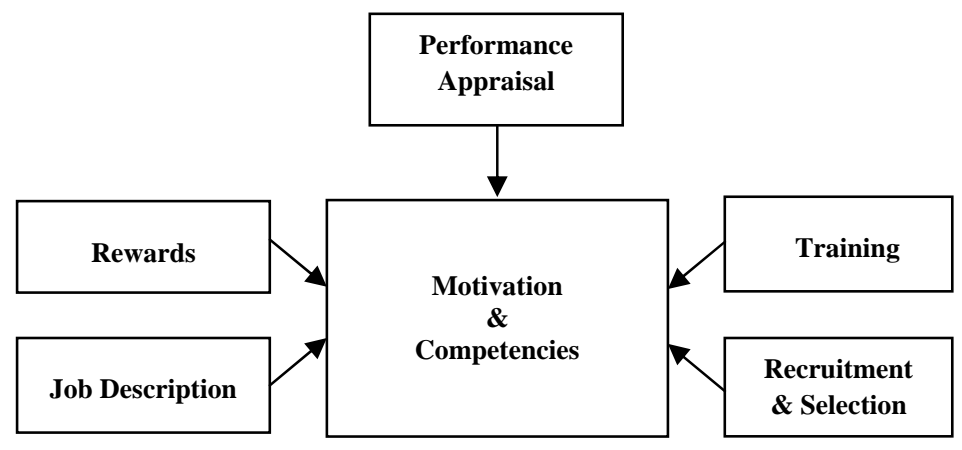




\section{Methodology}

Sample size was 100 including white-collar employees' body of segment head in the factory (top level), officers (mid level) and the technicians (frontline) from the white-collar employees (WCEs) and blue-collar employees (BCEs) altogether. Participants were the current employees of a leading battery manufacturer in Bangladesh. The name of the firm is promised not to disclose due to ethical obligations. Of them, 50 were from WCEs and 50 were from BCEs. As this is a production firm so as most of the employees were male. Employees' age ranges from 34 years to 50 years. The average tenure of their job was 5 years and the lowest was 1 year. Questionnaire was divided into seven sections and designed to be scale rated. The items of each section were in the form of statements that were direct, simple and concise. The participants had to tick in the boxes provided beside each item according to the extent of their agreement (scale provided at the beginning of the questionnaire). Scale rating provided was: $1=$ 'Strongly Disagree', 2='Disagree' 3='Neutral', 4='Agree', $5=$ 'Strongly Agree'. The dependent variables are motivation and competencies and independent are performance appraisal, rewards, training, job description, and selection process. Data obtained is analyzed with SPSS for Windows 11.5. To measure the reliability of the survey tool, Cronbach's alpha value was calculated. In order to test the hypotheses the analyses of Pearson Correlation and linear regression were used.

\section{Factor Analysis}

After obtaining data, reliability test (Table 1a and Table 1b) was conducted. This helped to know the degree to which the items in each section were consistent with each other. This is vital as reliability is a prerequisite for validity which is a measure for the degree of relation between the items assessed and actual results. By considering an alpha value of 0.8 and above, inconsistent items in the questionnaire were eliminated and the reliability test was rerun via factor analysis. The reason for such high alpha value for the other variables may have been due to the consistency in the results for each item which ranged from neutral (3) to agree (4) in most cases. Factor Analysis using data reduction was carried out to eliminate the inconsistent items with low coefficient values and to have alpha value greater than 0.8 .

\section{Findings}

\section{Descriptive Statistics}

The mean value of each variable (Table 1a and Table 1b) shows that results varied mostly from 'Neutral' to 'Agree'. With respect to WCEs, performance appraisal has the highest mean of 4.6 with the least standard deviation, and competencies as 4.1 with the highest standard deviation of 0.82 . This shows that WCEs are keener on their achievements being recognized and are highly motivated and driven to work harder. Hypothesis 1 (Table 1a and Table 1b) states that perception of effective performance appraisal practice is positively related to motivation and competencies within WCEs and BCEs. As displays across table $1 \mathrm{a} \& 1 \mathrm{~b}$ that performance appraisal is significantly positively related with competencies $\left(\mathrm{r}=.43^{* *}\right)$ alone but not with motivation with regard to WCEs and it has no relationship either competencies or motivation with regard to BCEs. Hypothesis 1 is partially accepted. 
Table 1a. Mean, standard deviations, correlations and reliabilities of WCEs

\begin{tabular}{llllllllll}
\hline Variables & Mean & SD & 1 & 2 & 3 & 4 & 5 & 6 & 7 \\
\hline 1. Performance Appraisal & 4.6 & .44 & $\mathbf{( . 8 1 )}$ & & & & & & \\
2. Rewards & 4.2 & .61 & .02 & $\mathbf{( . 8 )}$ & & & & & \\
3. Job Description & 4.1 & .66 & $-.41^{* *}$ & .04 & $\mathbf{( . 8 1 )}$ & & & & \\
4. Training & 4.3 & .71 & $.4^{* *}$ & -.07 & -.13 & $\mathbf{( . 8 2 )}$ & & & \\
5. Selection Process & 4.1 & .77 & .21 & .01 & -.11 & $.41^{* *}$ & $\mathbf{( . 8 1 )}$ & & \\
6. Motivation & 4.4 & .61 & .07 & .16 & .03 & .01 & .04 & $\mathbf{( . 8 )}$ & \\
7. Competencies & 4.1 & .82 & $.43^{* *}$ & -.03 & -.03 & .24 & .24 & .01 & $\mathbf{( . 8 )}$ \\
\hline
\end{tabular}

$N=50, * * p<.01$

Hypothesis 2 states that rewards are positively related to motivation and competencies within WCEs and BCEs. Rewards have no relationship either with motivation or competencies with regard to both cohorts. Thus the Hypothesis is rejected. Hypothesis 3 states that training is positively related to motivation and competencies within WCEs and BCEs. Job descriptions have no relationship either with motivation or competencies with regard to both cohorts. Thus the Hypothesis is rejected. Hypothesis 4 states that an appropriate job description is positively related to motivation and competencies within WCEs and BCEs.

Table 1b. Mean, standard deviations, correlations and reliabilities of BCEs

\begin{tabular}{lccccccccc}
\hline Variables & M & SD & \multicolumn{1}{c}{1} & \multicolumn{1}{c}{2} & 3 & 4 & 5 & 6 & 7 \\
\hline 1. Performance Appraisal & 4.2 & .91 & $\mathbf{( . 8 )}$ & & & & & & \\
2. Rewards & 4.2 & .61 & -.19 & $\mathbf{( . 8 1 )}$ & & & & & \\
3. Job Description & 4.1 & .63 & .12 & .06 & $\mathbf{( . 8 1 )}$ & & & & \\
4. Training & 4.3 & .66 & -.14 & -.13 & .05 & $\mathbf{( . 8 2 )}$ & & & \\
5. Selection Process & 4.4 & .72 & .25 & .001 & .17 & .002 & $\mathbf{( . 8 1 )}$ & & \\
6. Motivation & 4.2 & .76 & .05 & .09 & .12 & -.04 & -.09 & $\mathbf{( . 8 )}$ & \\
7. Competencies & 4.3 & .79 & .05 & .12 & -.17 & $.28^{*}$ & -.12 & -.03 & $\mathbf{( . 8 )}$ \\
\hline
\end{tabular}

$N=50,{ }^{*} p<.05$

Training has no relationship either with motivation or competencies with regard to WCEs but it is significantly related with competencies with regard to BCEs. Thus the Hypothesis is partially accepted. Hypothesis 5 states that right and timely selection process is positively related to motivation and competencies within WCEs and BCEs. Selection process has no relationship either with motivation or competencies with regard to both cohorts. Thus the Hypothesis is rejected.

\section{Regression Analysis}

Hypothesis 1 (Table $2 \mathrm{a}$ and Table $2 \mathrm{~b}$ ) predicts that performance appraisal is positively related to motivation and competencies with regard to WCEs and BCEs employees. Regression results for WCEs partially accepted for motivation and fully accepted for competencies where, $\beta_{1}=.07, \beta_{2}=.43$ the changes in the variables are affected. For BCEs, the 
alternate Hypothesis is partially accepted for motivation as well as competencies where, $\beta_{3}=.05, \beta_{4}=.05$, the changes in the variables are affected.

Table 2a. Regression results of job analysis affecting motivation and competencies of WCEs

\begin{tabular}{|c|c|c|c|c|c|c|c|c|}
\hline \multirow[t]{2}{*}{ Variables } & \multicolumn{4}{|c|}{ Motivation } & \multicolumn{4}{|c|}{ Competencies } \\
\hline & $\beta_{1}$ & $\mathrm{~T}$ & $\mathrm{~F}$ & $\mathrm{AR}^{2}$ & $\beta_{2}$ & $\mathrm{~T}$ & $\mathrm{~F}$ & $\mathrm{AR}^{2}$ \\
\hline Performance Appraisal & $.07 *$ & 5.4 & .29 & .02 & $.43^{*}$ & 3.3 & 11.13 & .17 \\
\hline Rewards & $.16^{*}$ & 8.5 & 1.3 & .01 & $-.03 *$ & 5.2 & .05 & .02 \\
\hline Training & $.03 *$ & 8.4 & .06 & .01 & $-.03 *$ & 5.8 & .04 & .02 \\
\hline Job Description & $.01 *$ & 8.3 & .01 & .02 & $.49 *$ & 2.6 & 15.4 & .22 \\
\hline Selection Process & $.04 *$ & 9.7 & .09 & .01 & $.24 *$ & 4.9 & 3.04 & .04 \\
\hline
\end{tabular}

Hypothesis 2 predicts that rewards are positively related to motivation and competencies with regard to WCEs and BCEs. Regression results for WCEs, the alternate Hypothesis is fully accepted for motivation but rejected for competencies where, $\beta_{1}=.16$, $\beta_{2}=-.03$, the changes in the variables are affected. For BCEs, the alternate Hypothesis is partially accepted for motivation and fully accepted for competencies where, $\beta_{3}=.09, \beta_{4}=.12$, the changes in the variables are affected. Hypothesis 3 (Table 2a and Table 2b) predicts that training is positively related to motivation and competencies for WCEs and BCEs. Regression results for WCEs, the alternate Hypothesis is partially accepted for motivation but rejected for competencies where, $\beta_{1}=.03, \beta_{2}=-.03$, the changes in the variables are affected. For BCEs, the alternate Hypothesis is accepted for motivation but rejected for competencies where, $\beta_{3}=.12, \beta_{4}=-.16$, the changes in the variables are affected.

Table 2b. Regression results of job analysis affecting motivation and competencies of BCEs

\begin{tabular}{|c|c|c|c|c|c|c|c|c|}
\hline \multirow[t]{2}{*}{ Variables } & \multicolumn{4}{|c|}{ Motivation } & \multicolumn{4}{|c|}{ Competencies } \\
\hline & $\beta_{3}$ & $\mathrm{~T}$ & $\mathrm{~F}$ & $\mathrm{AR}^{2}$ & $\beta_{4}$ & $\mathrm{~T}$ & $\mathrm{~F}$ & $\mathrm{AR}^{2}$ \\
\hline Performance Appraisal & $.05 *$ & 8.4 & .15 & .02 & $.05^{*}$ & 8.5 & .16 & .02 \\
\hline Rewards & $.09^{*}$ & 6.2 & .46 & .01 & $.12 *$ & 6.4 & .66 & .01 \\
\hline Training & $.12 *$ & 5.1 & .69 & .01 & $-.16^{*}$ & 7.2 & 1.4 & .01 \\
\hline Job Description & $-.04 *$ & 6.1 & .07 & .02 & $.28 *$ & 4 & 4.2 & .06 \\
\hline Selection Process & $-.09 *$ & 6.7 & .42 & .01 & $-.18^{*}$ & 7.5 & 7.5 & .02 \\
\hline
\end{tabular}

Hypothesis 4 predicts that job description is positively related to motivation and competencies with regard to WCEs and BCEs. Regression results for WCEs, the alternate Hypothesis is partially accepted for motivation and entirely for competencies. There is positive relationship between motivation, competencies and job description where, $\beta_{1}=.01$, $\beta_{2}=.49$ the changes in the variables are affected. For BCEs, the alternate Hypothesis is not accepted for motivation but totally accepted for competencies where, $\beta_{3}=-.04, \beta_{4}=.28$, the changes in the variables are not affected. Hypothesis 5 predicts that recruitment and selection process is positively related to motivation and competencies for WCEs and BCEs. Regression results for WCEs, the alternate Hypothesis is partially accepted for motivation but wholly accepted for competencies so it proves first Hypothesis. There is positive relationship 
between motivation and selection process where, $\beta_{1}=.04, \beta_{2}=.24$. For BCEs, the alternate hypothesis is not accepted for motivation and competencies where, $\beta_{1}=-.09, \beta_{2}=-.18$, the changes in the variables are not affected.

\section{Discussion}

The study found significant correlations of performance appraisal and training with competencies with regard to white-collar and blue-collar employees respectively. It means an increased level competency is positively related with performance management. Besides, training is also related proportionately with competencies of employees in the studied firm. This was congruent with research outcome reported by Glazerman (2010). In fact, objective performance management can heighten competencies that might work as a source of selfmotivation. Job description is an organization's process of defining strategy, or direction, and making decisions on allocating its resources to pursue the strategy including its capital and employees from the job and the job responsibilities. The positive results in regard to the job description from both cohorts $\left(\beta_{2}=.49^{*} ; \beta_{4}=.28^{*}\right)$ provide notion to reshuffle existing job while undermining less important task. The study discloses $\left(\beta_{2}=.24 *\right)$ that selection process is important to inculcate competencies for white collar employees. It is vital for firm to attract large talent pool at the outset of recruitment process. Rewards and promotion are inevitable to enhance employee's performance $\left(\beta_{1}=.16^{*} ; \beta_{4}=.12^{*}\right)$ and if employees perform well then that would be deemed as a source of competitive advantage for the firm in the long-run. The result indicates that training affects competencies with regard to blue-collar employees which lead towards the initiative taken by firm to create avenues for more training and development. Though motivation is an important criterion and recognized well by the employees of the firm. White collar employees could be more flexible to let the blue collar employees understand about the positive effect of the motivation. The study reports that the variables are interdependent and both cohorts acknowledge the positive perception of job analysis to capitalize knowledge, skills and abilities to sustain business in the studied firm. By and large, the study found significant perceptual differences in terms of performance appraisal and training with regards to white-collar and blue-collar employees. Other variables like rewards, selection process and job description have no relationship with motivation and competencies.

\section{Conclusion}

It is observed from the study that maximum influence on motivation and competencies are caused by performance appraisal, and training since both white collar and blue collar employees accorded it substantially. On the other hand, rewards, selection process and job description have less effect on competencies and motivation. Therefore, perception of job analysis irrespective of position is very crucial to pursue everyday's task and to carry out most important job frequently rather than casual tasks. It is recognized when objective performance appraisal is being practiced, rewards and training are involved rather than job description and motivation. White collar employees especially top management could equally render due attention to illustrate job description and refocus selection process because workers may not perceive the importance of job outright but in future it would contribute better performance. The study skims off more rooms to spare for research. It identifies perceptual differences and relationship of performance appraisal, reward, training, job description, and selection process with employee's motivation and competencies. More research may examine strategic integration of all these determinants to human resource management. Besides, other internal as well as external factors might trigger perception of job analysis with motivation and competencies of the employees which was beyond the 
present study. Though the study was confined to a single firm in manufacturing industry and the sample size was small $(N=100)$, to have comprehensive idea sample size could have been bigger. Future research may consider not only using multiple stakeholders to increase data reliability but also to undertake more firms both in manufacturing and service industry alike.

\section{References}

Armstrong, M. (2002). Employee Reward, $3^{\text {rd }}$ edition. London, CIPD

Arthur, W., Bennett, W., Edens, P. S., and Bell, S. T. (2003). Effectiveness of training in organizations: A meta-analysis of design and evaluation features. Journal of Applied Psychology, 88, 234-245.

Bach, S. (2005). Managing Human Resources-Human Resources in Transition, Oxford, Blackwell.

Barney, J. (1995). 'Looking inside for competitive advantage'. Academy of Management Executive, 9(4), 49-81.

Bitter, M. E., and Gardner, W. L. (1995). A mid-range of the leader/member attribution process in professional service organizations: The role of the organizational environment and impression management. In M.J. Martinko (Ed.), Attribution theory: An organizational perspective. Delray Beach, FL: St. Lucie Press.

Burns, N., and Groves, S. (2001). The practice of nursing research, conduct, critique \& utilization (4th ed). Toronto, Ontario: W. B. Saunders Company.

Cardy, R. L., and Dobbins, G. H. (1994). Performance Appraisal: Alterative Perspectives, First edition. South-Western.

Cascio, W .F. (1996). The changing world of work: Competencies for the future. In Human Capital: An innovative whole-person approach to competency assessment. Washington, DC: U.S. Office of Personnel Management, Personnel Resources and Development Center.

Cascio, W. F., and Aguinis, H. (2005). Applied psychology in human resource management $\left(6^{\text {th }}\right.$ ed. $)$. Upper Saddle River, NJ: Pearson Prentice Hall.

Cook, J. and Crossman, A. (2004). 'Satisfaction with performance appraisal systems'. Journal of Managerial Psychology, 19(5), 526-541.

Dowling, P., Welch, D., and Schuler, R. (1999). International dimensions of human resources. Cincinnati, OH: South Western College Publishing.

Drucker, P.F. (1994). Managing in Turbulent Times, Oxford: Butterworth-Heinemann.

Drucker, P. (1999). Management challenges for the 21st century. New York: Harper Collins. Dubinsky, A. J., Skinner, S. J., and Whittler, T. E. (1989). Evaluating sales personnel: An attribution theory perspective. Journal of Personal Selling and Sales Management, 9(2): 9-21.

Erdogan, B. (2002). 'Antecedents and consequences of justice perceptions in performance appraisals'. Human Resource Management Review, 12(4), 555-578.

Glazerman, S. (2010). Evaluating Teachers: In S. Loeb, D. Goldhabe, D. Staiger, S. Raudenbush, \& G. Whitehurst, Education Policy (pp. 1-12). Washington: The Brookings Institution. 
Guthrie, J. (2007). Remuneration pays effects and work, in P. Boxall, J. Purcell and P. Wright (eds) The Oxford Handbook of Human Resource Management. Oxford, Oxford University Press

Hacker, C. (1997). The cost of poor hiring decisions and how to avoid them, HR Focus, 74(10), 13-14.

Harvey, R. J. (1991). Job analysis. In M. D. Dunnette \& L. Hough (Eds.), Handbook of Industrial and Organizational Psychology (2nd ed.). Palo Alto, CA: Consulting Psychologists Press.

Howard, A. (1996). The changing nature of work: Implications for assessment centers. The 24th International Congress on the Assessment Center Method, Washington, DC.

Ilgen, D. R., and Feldman, J. M. (1983). Performance appraisal: A process focus. Research in Organizational Behavior, 5(2), 141-197.

Jackson, S. and Schuler, R. S. (2003). Managing Human Resources through Strategic Partnership (8th edn). Canada: Thompson.

Katsanis, L. P., Laurin, J. P., and Pitta, D. A. (1996). How Should Product Managers be Evaluated in Emerging Product Management Systems? Journal of Product and Brand Management, 5(6), 3-20.

Landy, F. J., Shankster-Cawley, L. and Moran, S. K. (1995). Advancing personal selection and placement methods. In A. Howard (ed.), The Changing Nature of Work. San Francisco, CA, Jossey-Bass.

Lawler, E. (1994). From job-based to competency based organizations. Journal of Organizational Behavior, 15(1), 3-16.

Lawler, E. (2000). Rewarding Excellence: Pay strategies for the new economy. New York, Jossey-Bass

Lewis, P. (2006). Reward Management, in T. Redman and A. Wilkinson (eds) Contemporary Human Resource Management, 2nd edition. London, Financial Times/Pearson.

McNamara, C. (2000). Employee Job Descriptions. Jossey-Bass Inc. San Francisco.

Marchington, M. and Wilkinson, A. (2008). Human Resource Management at work: People management and development. London, CIPD

Moravec, M. (1996). 'Bringing performance management out of the Stone Age'.

Management Review, 85(2), 38-42.

Mullen, B. (2005). Co-mentoring: critical reflection in practice. AARE 2005 International

Education Research Conference. Melbourne: Australian Association for Research in Education.

Phillips, J. M., and Gully, S. M. (2009). Strategic Staffing, London. Pearson Education International.

Rich, A. (2000). Employees as investors/owners: Maximizing human capital net worth. Case study/panel discussion presented at Managing and Measuring Human Capital: Best Practices for Hiring, Developing and Preserving a Committed and Engaged Workforce, San Francisco. 
Robinson, D. G., and Robinson, J. C. (1989). Training for impact: How to link training to business needs and measure the results. San Francisco: Jossey-Bass.

Rodriguez, D., Patel, R., Bright, A., Gregory, D., and Gowing, M. K. (2002). Developing Competency Models to Promote Integrated Human Resource Practices, Human Resource Management, 41(3), 309-324.

Salas, E., and Stagl, K. C. (2009). 'Design Training Systematically and Follow the Science of Training', in E. Locke (ed.), Handbook of Principles of Organizational Behavior: Indispensible Knowledge for Evidence-Based Management, 2nd edn (Chichester: John Wiley \& Sons), pp. 59-84.

Salas, E.,Wilson, K., Priest, H., and Guthrie, J. (2006). 'Design, Delivery, and Evaluation of Training Systems', in G. Salvendy (ed.), Handbook of Human Factors and Ergonomics, 3rd edn (Hoboken, NJ: John Wiley \& Sons), pp. 472-512.

Schneider, B., and Konz, A. M. (1989). Strategic job analysis. Human Resources Management, 28(1), 51-63.

Smith, M., and Graves, C. (2002). Re-engineering recruitment to the accounting profession, Managerial Auditing Journal, 17(3), 13-31.

Stone, R., (2002). Human Resource WCEs, Fourth edition. Sydney. John Wiley \& Sons. Ulrich, D. (1997). Human resource champions. Cambridge, MA: Harvard Business School Press.

Wells, S. (2001). “Stepping Carefully,” HR Magazine 1, 44-49.

\section{Abbreviations used}

BCEs: Blue-collar employees

WCEs: White-collar employees

MNCs: Multinational Companies

*Earlier version of the paper was presented in $6^{\text {th }}$ International Knowledge Globalization Conference (IKGC) hold in Pune from January 5-7, 2012 and jointly organized by Flame University, India with Suffolk University, Boston, USA.

"Remaking the world is an insignificant task.... It is not world that must be remade, but man.

Albert Camus 